\title{
Implant materials modified by colloids
}

\author{
BeATA ZBoromirsKa-WNUKIEWICZ ${ }^{1}$, Witold WNUKIEWICZ ${ }^{2}$, KRZYSZTOF KOGUT ${ }^{1 *}$, JAN \\ WNUKIEWICZ ${ }^{2}$, ROMAN RUTOWSKI ${ }^{2}$, JERZY GOSK ${ }^{2}$, KRZYSZTOF KASPRZYK ${ }^{1}$ \\ ${ }^{1}$ Electrotechnical Institute Division of Electrotechnology and Materials Science in Wrocław \\ ${ }^{2}$ Poland, Wrocław Medical University
}

\begin{abstract}
Recent advances in general medicine led to the development of biomaterials. Implant material should be characterized by a high biocompatibility to the tissue and appropriate functionality, i.e. to have high mechanical and electrical strength and be stable in an electrolyte environment - these are the most important properties of bioceramic materials. Considerations of biomaterials design embrace also electrical properties occurring on the implant-body fluid interface and consequently the electrokinetic potential, which can be altered by modifying the surface of the implant. In this work, the surface of the implants was modified to decrease the risk of infection by using metal colloids. Nanocolloids were obtained using different chemical and electrical methods. It was found that the colloids obtained by physical and electrical methods are more stable than colloids obtained by chemical route. In this work the surface of modified corundum implants was investigated. The implant modified by nanosilver, obtained by electrical method was selected. The in vivo research on animals was carried out. Clinical observations showed that the implants with modified surface could be applied to wounds caused by atherosclerotic skeleton, for curing the chronic and bacterial inflammations as well as for skeletal reconstruction surgery.
\end{abstract}

Keywords: implant; electrokinetic potential; nanosilver; bioceramic

(C) Wroclaw University of Technology.

\section{Introduction}

Demands for implant materials applied in medicine led to significant progress in this field. Biomaterials cannot be rejected by the immune system when they are implanted into the living organism of a patient. Therefore, during testing of the materials, it is very important to verify their bioconformity as well as biofunctionality. Generally, it involves the development of a structure, which will be able to realize a specific function of the tissue and suppress the body immune system at the same time. Despite significant progress, challenges remain for development of materials with the new improved implant-tissue-body fluid interphase properties. However, implanted materials carry a risk of infection. Foreign body implantation carries the hazards of:

- corrosion and degradation of implant
materials,

*E-mail: k.kogut@iel.wroc.pl
- infection of the tissue around the implant,

- development of chronic infection.

Silver and its compounds as generally acting antiseptics have been known and used in medicine for years [1]. Already Phoenicians used silver bottles to store water or wine in order to preserve their freshness. In the $19^{\text {th }}$ century, silver compounds were used as a popular medication for tetanus, or rheumatism. At the beginning of the $20^{\text {th }}$ century, just before the advent of antibiotics, silver was the medicine for fever and infective meningitis. At the end of the $20^{\text {th }}$ century, due to the development of nanotechnology, silver again, but in a form of nanosilver, found its implementation opportunity in medicine. Anti-bacterial properties of silver depend on its form and the applied dose [2]. Exemplary use of silver in contemporary medicine is its usage for modification of orthopedic implants surfaces [3-6].

Silver is of interest of many researchers. They point out both the positive and negative sides of using silver in medicine. This makes that the 
Table 1. Crystal sizes determined by the X-ray diffraction method.

\begin{tabular}{|c|c|c|c|c|c|c|c|}
\hline \multicolumn{2}{|l|}{$\stackrel{心}{\approx}$} & \multicolumn{5}{|c|}{$\begin{array}{l}\text { Residue from the suspension obtained } \\
\text { with } 1.1 \mathrm{~kJ} \text { energy }\end{array}$} & \multirow[b]{2}{*}{5454} \\
\hline Intensity I & 15041 & 6306 & 2912 & 4431 & 1248 & 895 & \\
\hline Diffraction angle $2 \Theta$ & 44.9 & 52.4 & 77.3 & 94.1 & 99,8 & 123.9 & 148.3 \\
\hline$\simeq$ Crystallite size D $[\AA]$ & 190.2 & 148.6 & 166.6 & 125.1 & 130.2 & 106.6 & 119.6 \\
\hline
\end{tabular}

implants surface modification leaves the topic open for selection of dose and method for safe and effective application in medicine. Materials used in the contemporary medicine, when classified according to the structure, can be divided into four groups: metals, organic polymers, ceramic materials and composites.

Corundum implants are made of a material that can be used as antibiotic carrier in bones surgery. It is characterized by high mechanical strength and, even after tissue outgrowth, has high elastic modulus, which is a result of good biomechanical cooperation with the bone [7].

The aim of this work was modification of surfaces of ceramic implants with the use of silver colloid so as they attained bacteriostatic properties. The low-porosity corundum-ceramics implants were selected for this experiment.

\section{Experiment}

The corundum samples composed of $95 \%$ $\mathrm{Al}_{2} \mathrm{O}_{3}, 3 \% \mathrm{MgO}$ and $2 \% \mathrm{CaO}$ were sintered at $1550{ }^{\circ} \mathrm{C}$. The surface modification of the corundum samples was made using the colloidal silver, which was obtained in the Electrotechnical Institute in Wrocław using silver wire explosion method. The concentration of colloidal silver was $60 \mu \mathrm{g} / \mathrm{mL}$. Modification was made in two sequential processes of penetrating corundum pores by filtering colloidal silver for 30 minutes. The processes were carried out in a vacuum chamber under a pressure of about $50 \mathrm{hPa}$. Infiltrated samples were dried for 24 hours in air and then in a cabinet dryer sequentially for $4 \mathrm{~h}$ at $70{ }^{\circ} \mathrm{C}$ and $110^{\circ} \mathrm{C}$, respectively.

The adequate knowledge on nanoparticles nature allows verifying their properties according to their potential application. Biologically active nanoparticles can be applied for four different purposes: disinfection (antiseptic), prevention, treatment and immunostimulation.

Stimulation of the answer a living organism defense system is a undeniably distinguishing feature of many nanoparticle preparations. As the living organism are characterized by the properties such as energy transformation ability, reproduction, species and individual defense ability, the nanoparticle confections can change or destroy the survival and preserve the properties of many microorganisms. Microorganisms cannot create the mechanism against them [3]. The finer the nanoparticle material, the better its immunostimulating abilities [4].

\section{Determination of the size and shape of the colloidal silver particles}

For the size and shape of the colloidal silver particles determination, three different methods were used:

- microscope photography with the use of AFM and TEM microscopes, (Fig. 1 and Fig. 2),

- laser diffraction method, with the use of Zetasizer NICOMP (Fig. 3),

- X-ray diffraction method with the use of powder diffractometer DRON-2 using filtered $\mathrm{Fe}$ Co radiation (Table 1).

As can be seen, all the three methods show similar results, which proves that silver particles are really nano-sized. Zeta potential was measured using a Zetasizer 3000 - Malvern Instruments (UK) with the following parameters: the range of particle 

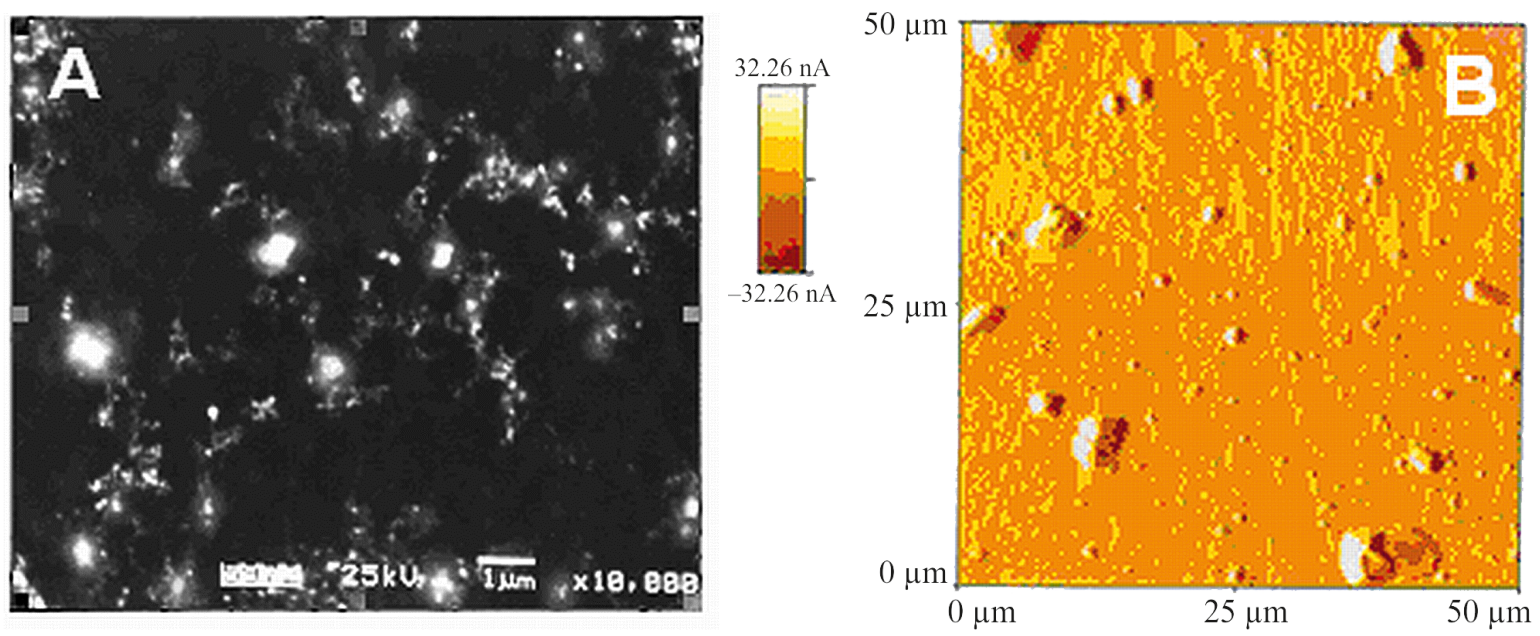

Fig. 1. The size and shape of the particles separated from the stable colloid. A - SEM microscope image, B AFM microscope image.
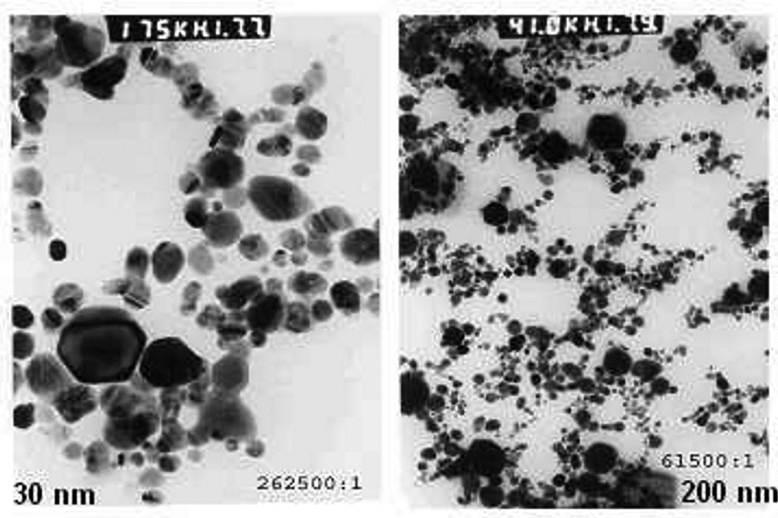

Fig. 2. The size and shape of the particles separated from the stable colloid-TEM microscope images.

size: $5 \mathrm{~nm}$ to $30 \mu \mathrm{m}$, medium conductivity: from 0 to $30 \mathrm{mS} / \mathrm{cm}, \mathrm{pH}$ : from 2 to 12 , measurement temperature: from 10 to $70{ }^{\circ} \mathrm{C}$.

For the electrokinetic potential measurement of the colloidal silver, the samples were dispersed in aqueous solutions of different $\mathrm{pH}$ at temperature of $25{ }^{\circ} \mathrm{C}$. The measurements were performed for one minute, and the final result was calculated as an average of 30 measurements. The results are shown in Fig. 4.

In Fig. 5, the scanning microscope images of corundum ceramics surface before modification
(Fig. 5A) and after modification by colloidal silver (Fig. 5B), are shown.

The samples prepared in accordance with the described procedure were implanted to rabbits and Wistar rats. In vivo research did not show any pathological processes in the bone tissue area in the vicinity of the implant. However, for the assessment of suitability of the corundum ceramics infiltrated by colloidal silver for bones implants application, the implant-tissue-body fluid interphase interactions should be further investigated.

\section{Discussion}

In this work, the size and shape of colloidal silver particles were estimated by the microscopic, X-ray and laser diffraction methods. Particles size estimated by that methods was similar and of an order of several nanometers.

An increase in the surface of the colloidal silver in relation to its mass caused that a larger amount of atoms had a contact with the external environment containing living substances.

An improvement in nanoparticle material properties can be obtained by its fragmentation. In order to determine the stability of colloidal silver obtained by "silver wire explosion" method and its tendency to agglomeration and sedimentation, 


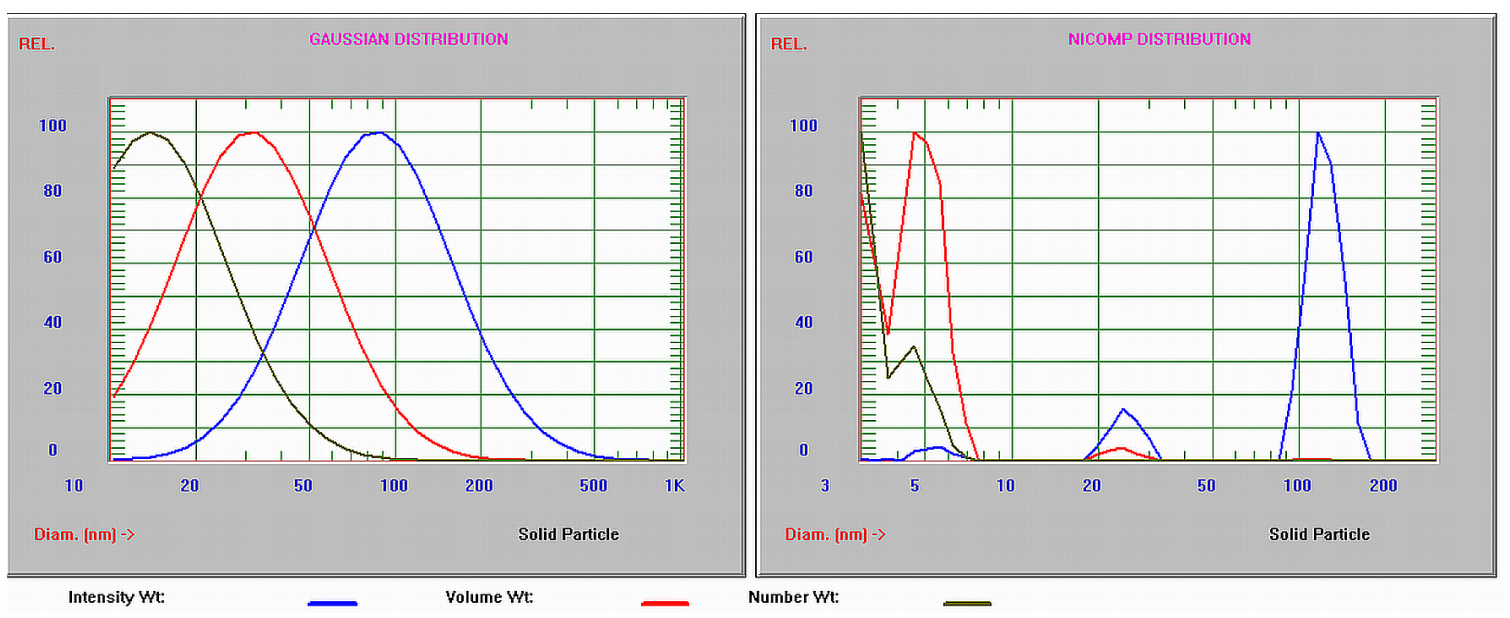

Fig. 3. Gauss and Nicomp distributions of stable colloidal silver.

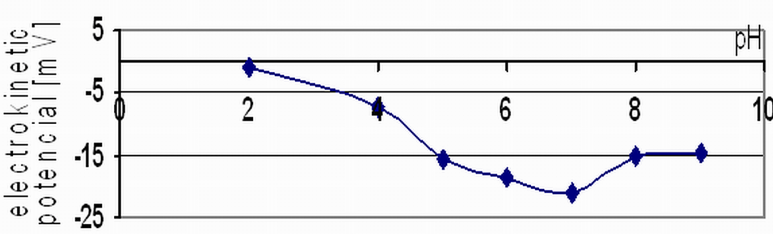

Fig. 4. Electrokinetic potential of colloidal silver in the function of $\mathrm{pH}$.

the electrokinetic potential measurements were carried out.

A solution characterized by high stability has the electrokinetic potential higher than $+30 \mathrm{mV}$ or lower than $-30 \mathrm{mV}$. In this research the silver samples dispersed in solution with different $\mathrm{pH}$, at temperature $25^{\circ} \mathrm{C}$ were used. The highest stability exhibited the colloidal silver solution obtained at $\mathrm{pH}$ $\sim 7$. The value of the potential was about $-21 \mathrm{mV}$ (Fig. 4).

In Fig. 5, the surface of corundum ceramics infiltrated by colloidal silver in the vacuum chamber at $50 \mathrm{hPa}$, is shown. In the image obtained with a scanning electron microscope, the areas with silver agglomerates are indicated. The samples prepared in such way were implanted to rabbits and Wistar rats. In vivo research did not show any pathological processes in the bone tissue area in the vicinity of the implant. However, for the assessment of suitability of the corundum ceramics infiltrated by colloidal silver for bones implants application, the implant-tissue-body fluid interphase interactions should be further investigated. The type of the composite interactions with bone tissue - osteoinductive or osteoconcutive - should be determined. This interaction depends on the shape and size of the porous in ceramics.

For a comprehensive assessment of the corundum ceramics infiltrated by colloidal silver and possibilities of its clinical application, an analysis of the influence of colloidal silver particles on life processes in tissues at molecular level and a long term study of the effect of the colloidal silver as a modificator of the corundum ceramics, should be performed.

\section{Conclusions}

- The particle size estimated by microscope, $\mathrm{X}$-ray and laser diffraction were similar. The particle size of the colloidal silver was about several nanometers.

- To determine the stability of the colloidal silver solution obtained by "silver wire explosion" method and its tendency to agglomeration and sedimentation, the electrokinetic potential measurements were carried out. The colloidal silver solution exhibited the highest stability at $\mathrm{pH} \sim 7$. The value of the potential was about $-21 \mathrm{mV}$. 

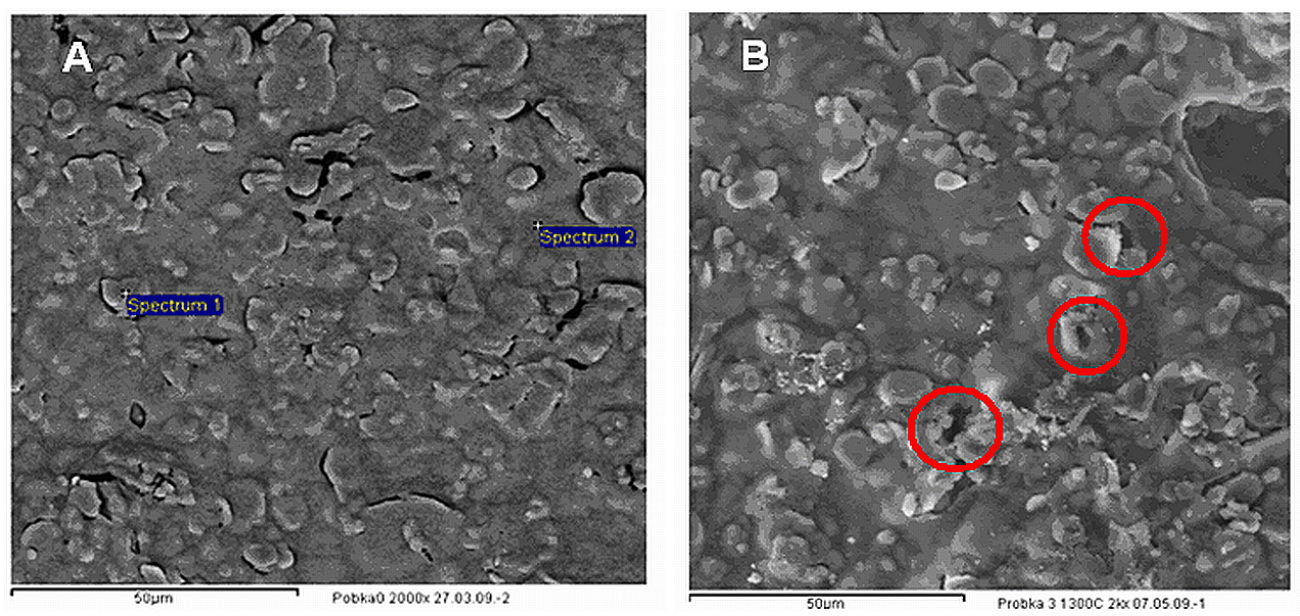

Fig. 5. Scanning microscope image of corundum ceramics surface designed for implantation. A - corundum ceramics, B - corundum ceramics infiltrated by colloidal silver.

- In figures presenting the scanning microscope images, the areas with silver agglomerate have been indicated

- The samples prepared in such a way were implanted to rabbits and Wistar rats. In vivo research has not shown any pathological processes in the bones tissue area in the vicinity of the implant.

- For a comprehensive assessment of the suitability of the corundum ceramic infiltrated by colloidal silver for bones implants application, the implant-tissue-body fluid interphase interactions should be further investigated.

\section{Acknowledgements}

The research was supported by the Wrocław Research Centre EIT + under the project "The Application of Nanotechnology in Advanced Materials" - NanoMat (POIG.01.01.0202-002/08) financed by the European Regional Development Fund (Innovative Economy Operational Programme, 1.1.2).

\section{References}

[1] Gosheger G., Hardes J., Ahrens H., StreitBurger A., Buerger H., Erren M., Gunsel A., Kemper F.H., Winkelmann W., Von Eiff C., Biomaterials, 25 (2004), 5547.

[2] Collinge C.A., Goll G., Seligson D., Easley K.J., Orthopedics, 17 (5) (1994), 445.

[3] Tweden K.S., CAmeron J.D., Razzauk A.J., J. Heart Valve Dis., 6 (1997), 553.

[4] LASKOwski S., Doctoral Thesis, Wroclaw University of Technology, Wrocław, 2007.

[5] Wnukiewicz W., Doctoral Thesis, Wroclaw Medical University, 2011.

[6] ZBoromirska-WNuKiewicz B., Kogut K., WNUKIEWICZ J., WNUKIEWICZ W., KASPRZYK K., Arch. Metall. Mater., 54 (4), (2009), 1005.

[7] Rusiecki M., Pielka S., Rutowski R., Staniszewska-Kuś J., Paluch D., Solski L., Polim. Med., 34 (2) (2004), 39. 